\title{
$140 \mathrm{~W}$ 급 전력 증폭 소자의 병렬 확장형 GaN HEMT 대신호 모델
}

\section{Scalable GaN HEMT Large-Signal Model for 140-W Power Devices}

\author{
권 호 상·정 종 헌 ${ }^{*}$ 김 동 욱** \\ Ho-Sang Kwon · Jong-Hun Jung* · Dong-Wook Kim** \\ 요 약
}

본 논문에서는 $140 \mathrm{~W}$ 급 전력 증폭 소자에 대한 병렬 확장형 GaN HEMT 대신호 모델을 제시하였다. 80-핑거 $\mathrm{GaN}$ HEMT 소자에 대한 모델은 8개의 단위 소자 모델이 병렬 확장형으로 연결된 구조이며, 단위 소자의 대신호 모델은 $\mathrm{AMCAD} \mathrm{FET}$ 모델을 기반으로 제작되었다. 단위 소자는 10-핑거 GaN HEMT 소자와 게이트, 드레인 패드로 구성되어 있다. $\mathrm{AMCAD}$ 사의 IVCAD 프로그램과 Keysight사의 PNA-X 네트워크 분석기를 이용하여 단위 소자의 GaN HEMT 대신 호 모델 파라미터를 추출하였다. 단위 소자의 대신호 모델은 10-핑거 소자를 온-웨이퍼 로드-풀 측정을 수행하여 검증하 였으며, 대면적 소자의 대신호 모델은 80-핑거 소자를 패키징한 다음 로드-풀 측정을 수행하여 검증하였다.

\section{Abstract}

In this study, a scalable GaN HEMT large-signal model for 140 -W power devices is presented. The large-signal model of an 80 -finger GaN HEMT includes eight unit device models in parallel, and the large-signal model of the unit device is based on the AMCAD - FET model. The unit device includes a 10-finger GaN HEMT, a gate pad, and a drain pad. Parameters for the unit GaN HEMT model were extracted using an IVCAD program of AMCAD and a Keysight PNA-X network analyzer. The unit GaN HEMT model was verified through on-wafer load-pull measurements, and the large-signal GaN HEMT model of the large-sized 80-finger device was verified through load-pull measurements of the packaged device.

Key words: GaN HEMT, Large-Signal Model, AMCAD FET Model, Power Amplifier, Load-Pull Measurement

\section{I. 서 론}

$\mathrm{GaN} H E M T$ 소자는 높은 전력 밀도, 열 전도도, 항복 전압 및 전자 이동도 등의 특성을 가지고 있어 최근 능동 위상 배열 레이다 또는 이동통신용 기지국 장비 등에서 $\mathrm{RF}$ 송신 증폭기로 많이 사용되고 있다 ${ }^{[1]-[3]}$.
$\mathrm{GaN} \mathrm{HEMT} \mathrm{소자를} \mathrm{이용하여} \mathrm{전력} \mathrm{증폭기를} \mathrm{설계하고}$ 제작하기 위해서 소자의 비선형 특성을 정확하게 모사해 줄 수 있는 대신호 모델이 필수적이다. 대신호 모델을 제 작하기 위하여 일반적으로 온-웨이퍼 프로브 장비를 이 용하여 소자의 특성을 측정하고, 모델링 파라미터를 추출 한다. 높은 출력을 내는 대면적 소자의 경우, 온-웨이퍼

\footnotetext{
「이 연구는 국방과학연구소의 연구비 지원으로 연구되었음. 국방과학연구소(Agency for Defense Development)

*한화시스템(Hanwha Systems)

**충남대학교 전파정보통신공학과(Department of Radio and Information Communications Engineering, Chungnam National University)

- Manuscript received August 13, 2020 ; Revised September 20, 2020 ; Accepted November 16, 2020. (ID No. 20200813-072)

· Corresponding Author: Dong-Wook Kim (e-mail: dwkim21c@cnu.ac.kr)
} 
프로브 장비로 직접 측정하기 어렵기 때문에 측정 가능 한 작은 소자의 특성을 온-웨이퍼 프로브 장비로 측정하 여 GaN HEMT 대신호 모델을 제작한 다음 대면적 소자 모델로 확장하는 방법이 많이 사용되고 있다 ${ }^{[4] \sim[8]}$.

$\mathrm{GaN} \mathrm{HEMT}$ 소자의 게이트 수와 폭을 이용하여 확장 계수를 구하고, 드레인-소스 전류와 비선형 캐패시턴스 모델에 적용하여 대면적 소자의 모델을 구하는 방법이 최근 연구되고 있지만, 출력이 $10 \mathrm{~W}$ 이하의 비교적 작은 소자들에 대하여 적용되었다 ${ }^{[9]-[14]}$.

$\mathrm{GaN}$ HEMT 소자는 전력 밀도가 높으며, 소자 자체에 서 소모되는 전력에 의하여 발생하는 열로 인해 내부 온 도가 올라가게 되는 셀프-히팅 등의 열적인 특성이 소자 의 성능에 영향을 준다 ${ }^{[15]}$. GaN HEMT 소자의 트래핑 효 과는 분산에 의한 Pulsed-IV(PIV) 특성과 DC 특성의 차이 를 가져오며 소자의 비선형 특성에 영향을 준다 ${ }^{[16]}$.

본 논문에서는 GaN HEMT 소자의 열적인 특성과 트래 핑 효과를 모델링할 수 있는 $\mathrm{AMCAD}$ 사의 $\mathrm{IVCAD}^{\mathrm{TM}}$ 프로 그램[17],[18]을 이용하여 단위 소자의 대신호 모델을 제작한 다음 이것을 병렬 확장하여 $140 \mathrm{~W}$ 급 전력 증폭 소자의 $\mathrm{GaN}$ HEMT 대신호 모델을 제작하고 검증한 결과를 제시 하였다. 10-핑거 $\mathrm{GaN} \mathrm{HEMT} \mathrm{소자와} \mathrm{게이트,} \mathrm{드레인} \mathrm{패드}$ 가 포함된 단위 소자는 출력 전력이 $20 \mathrm{~W}$ 급인 소자로 정격 전류가 $\mathrm{DC} 2 \mathrm{~A}$ 인 온-웨이퍼 프로브 측정 시스템에 서 $\mathrm{AMCAD}$ 사의 IVCAD 프로그램과 Keysight사의 PNA-X 네트워크 분석기(VNA)를 이용하여 특성을 측정하고, 파 라미터를 추출하여 AMCAD FET 모델 기반 대신호 모델 을 제작하였다. 제작된 단위 소자 모델을 병렬 확장하여 80-핑거 GaN HEMT 소자의 대신호 모델을 얻었다. 10-핑 거 단위 소자에 대해서는 온-웨이퍼 로드-풀 측정을 수행 하고, 80-핑거 GaN HEMT 소자는 패키징한 다음 로드-풀 측정을 수행하여 제작된 대신호 모델의 유효성을 검증하 였다.

\section{II. 단위 소자 대신호 모델}

본 논문에서는 그림 1에 보이는 10-핑거 $\mathrm{GaN} \mathrm{HEMT}$ 소자의 비선형모델을 위하여 empirical compact model의 한 종류인 $\mathrm{AMCAD} \mathrm{FET}$ 모델을 사용하였으며, $\mathrm{IVCAD}^{\mathrm{TM}}$ 프로그램을 이용하여 파라미터를 추출하였다. $\mathrm{AMCAD}$

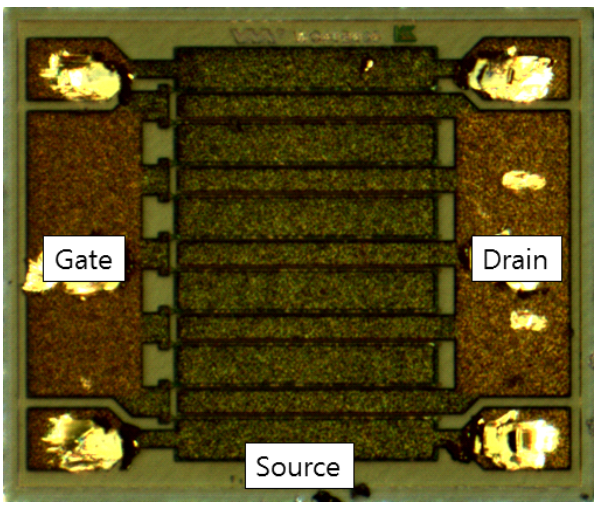

그림 1. 10-핑거 GaN HEMT 소자의 광학 현미경 사진

Fig. 1. Microphotograph of a 10-finger GaN HEMT.

FET 모델은 그림과 같은 등가 회로로 이루어져 있으며, 소신호 및 대신호 모델, 열 저항 모델, 트래핑 효과 모델 등을 위한 파라미터를 포함한다. 단위 소자의 게이트 폭 은 $10 \times 350 \mu \mathrm{m}$, 게이트 길이는 $0.4 \mu \mathrm{m}$ 이며, 단위 소자의 크기는 $830 \times 700 \mu \mathrm{m}$ 이다.

$\mathrm{AMCAD} \mathrm{FET} \mathrm{모델은} \mathrm{다음} \mathrm{식으로} \mathrm{표현되는} \mathrm{전류원} \mathrm{모}$ 델을 사용한다 ${ }^{[19],[20]}$.

$$
\begin{aligned}
& I_{d s}=U \tanh \left(\alpha V_{d s}\right) \\
& \alpha=\frac{1}{2}\left(\left(\alpha_{1}-\alpha_{2}\right) \tanh \left(-V_{g s}+V_{g 1}\right)+\left(\alpha_{1}+\alpha_{2}\right)\right) \\
& U=F a\left(I_{1}\left(V_{1}+\lambda\right)+\frac{V_{d s}-V_{d s p}}{R_{d s 0}}, R_{u}, U_{0}\right) \\
& V_{1}=F_{p}\left(V_{q s}, V_{d s}\right)
\end{aligned}
$$

여기서 $\alpha_{1}, \alpha_{2}, V_{g s 1} I_{1}, \lambda, V_{d s p}, R_{d s 0}$ 는 매개변수들이다. $F a$ 함수는 조절 가능한 전이 매개변수 $R_{u}$ 와 임의의 값 $U_{0}$ 로부터 아핀 함수(affine function)의 최소 극한을 결정한다. $F_{p}$ 함수는 두 변수 $\left(V_{g s}, V_{d s}\right)$ 를 가지는 n-차 다항식이다.

비선형 모델을 위하여 사용되는 캐패시턴스는 다음 식 으로 표현된다 ${ }^{[18],[19]}$.

$$
\begin{aligned}
& C_{g s}=C 0_{C g s}+\frac{C 1_{C g s}-C 0_{C g s}}{2} \times \\
& {\left[1+\tanh \left(A_{C g s}\left(V_{g s}+V m_{C g s}\right)\right)\right]-} \\
& \frac{C 2_{C g s}}{2}\left[1+\tanh \left(B_{C g s}\left(V_{g s}+V p_{C g s}\right)\right)\right]
\end{aligned}
$$




$$
\begin{gathered}
C_{g d}=C 0_{C g d}+\frac{C 1_{C g d}-C 0_{C g d}}{2} \times \\
{\left[1+\tanh \left(A_{C g d}\left(V_{g d}+V m_{C g d}\right)\right)\right]-} \\
\frac{C 2_{C g d}}{2}\left[1+\tanh \left(B_{C g d}\left(V_{g d}+V p_{C g d}\right)\right)\right] \\
C_{d s}=C 0_{C d s}+\frac{C 1_{C d s}-C 0_{C d s}}{2} \times \\
{\left[1+\tanh \left(A_{C d s}\left(V_{g s}+V m_{C d s}\right)\right)\right]-} \\
\frac{C 2_{C d s}}{2}\left[1+\tanh \left(B_{C d s}\left(V_{d s}+V p_{C d s}\right)\right)\right]
\end{gathered}
$$

여기서 $C 0_{x}, C 1_{x}, C 2_{x}, A_{x}, B_{x}, V m_{x}, V p_{x},(x=C g s$ 또 는 $C g d$ 또는 $C d s)$ 는 매개변수들이다.

일반적으로 $\mathrm{FET}$ 등가모델은 바이어스 전압에 영향을 받지 않는 extrinsic 성분과 바이어스 전압 조건에 영향을 받는 intrinsic 성분으로 나누어지며, 그림 2에서 $L_{g}, R_{g}$, $C_{p g}, R_{d}, L_{d}, C_{p d}, R_{s}, L_{s}$ 는 extrinsic 성분이며, 그림 2의 나머 지 성분들이 intrinsic 성분이다 ${ }^{[21]}$. Extrinsic 성분의 추출과 디임베딩은 선형 모델 추출에 앞서 이루어져야 하며, $\mathrm{VNA}$ 기반의 로드-풀 측정에서 얻어지는 $S$-파라미터를 이용한다. $V_{D S}=0 \mathrm{~V}, V_{g s}=$ open 또는 pinch-off인 동작점에서 측정되는 Cold FET $S$-파라미터를 이용하여 extrinsic 성분 을 구하고, 디임베딩을 통하여 intrinsic 성분을 구할 수 있 다 [19],[21] [23].

$\mathrm{AMCAD}$ FET 모델을 위한 파라미터는 온-웨이퍼 프로 브 장비에서 단위 소자를 측정하여 얻었으며, 선형 모델 을 위한 파라미터 값들을 표 1에 나타내었으며, 비선형 모델을 위한 파라미터 값들을 표 2 표 5에 나타내었다.

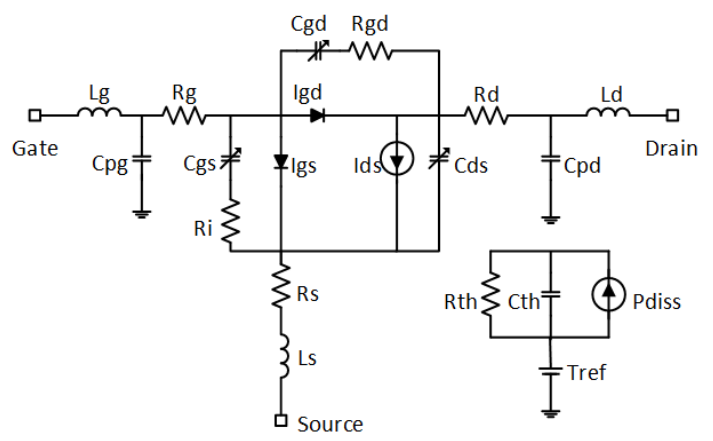

그림 2. $\mathrm{AMCAD} \mathrm{GaN} \mathrm{HEMT}$ 모델[19]

Fig. 2. AMCAD GaN HEMT model ${ }^{[19]}$.
표 1. GaN HEMT 단위 소자에 대하여 추출된 선형 모델 파라미터 값들

Table 1. Linear model parameters extracted for a $\mathrm{GaN}$ HEMT unit device.

\begin{tabular}{|c|c|}
\hline Parameter & Value \\
\hline$R_{g}$ & $1.59813 \Omega$ \\
\hline$L_{g}$ & $5.4128 \times 10^{-11} \mathrm{H}$ \\
\hline$C_{p g}$ & $4.181 \times 10^{-13} \mathrm{~F}$ \\
\hline$L_{s}$ & $1.2192 \times 10^{-12} \mathrm{H}$ \\
\hline$C_{p d}$ & $5.8412 \times 10^{-13} \mathrm{~F}$ \\
\hline$L_{d}$ & $5.8056 \times 10^{-11} \mathrm{H}$ \\
\hline$R_{s}$ & $6.1818 \times 10^{-3} \Omega$ \\
\hline$R_{d}$ & $6.6382 \times 10^{-2} \Omega$ \\
\hline$R_{i}$ & $3.7997 \times 10^{-1} \Omega$ \\
\hline$C_{d s}$ & $7.9262 \times 10^{-13} \mathrm{~F}$ \\
\hline$T_{a u}$ & $5.0698 \times 10^{-12} \mathrm{~s}$ \\
\hline$R_{g d}$ & $12.78365 \Omega$ \\
\hline$C_{g s}$ & $6.2963 \times 10^{-12} \mathrm{~F}$ \\
\hline$C_{g d}$ & $5.585 \times 10^{-13} \mathrm{~F}$ \\
\hline$G_{d s}$ & $5.1817 \times 10^{-2} \mathrm{~S}$ \\
\hline$G_{m}$ & $5.9062 \times 10^{-1} \mathrm{~S}$ \\
\hline & \\
\hline
\end{tabular}

표 2. GaN HEMT 단위 소자에 대하여 추출된 비선형 모 델 파라미터 값들(IV model)

Table 2. Nonlinear model parameters extracted for a $\mathrm{GaN}$ HEMT unit device(IV model).

\begin{tabular}{|c|c|}
\hline Parameter & Value \\
\hline$I_{d s s}$ & $3.265 \mathrm{~A}$ \\
\hline$V_{p 0}$ & $2.51156 \mathrm{~V}$ \\
\hline$V_{d s p}$ & $3.40066 \mathrm{~V}$ \\
\hline$V_{p h i}$ & $0.68007 \mathrm{~V}$ \\
\hline$A$ & 0.001 \\
\hline$B$ & 0.64 \\
\hline$M$ & 12.4876 \\
\hline$P$ & $6.4 \times 10^{-4}$ \\
\hline$W$ & 0.56869 \\
\hline AlphaGmd & 0.39565 \\
\hline$V_{g m}$ & $10.87527 \mathrm{~V}$ \\
\hline BetaGmd & 0.39846 \\
\hline$V_{d m}$ & $290.58298 \mathrm{~V}$ \\
\hline
\end{tabular}


THE JOURNAL OF KOREAN INSTITUTE OF ELECTROMAGNETIC ENGINEERING AND SCIENCE. vol. 31, no. 12, December. 2020.

표 3. GaN HEMT 단위 소자에 대하여 추출된 비선형 모 델 파라미터 값들 $\left(C_{g s}\right.$ model $)$

Table 3. Nonlinear model parameters extracted for a $\mathrm{GaN}$ HEMT unit device $\left(C_{g s}\right.$ model $)$.

\begin{tabular}{|c|c|}
\hline Parameter & Value \\
\hline$C_{0} C_{g d}$ & $2.54503 \times 10^{-12} \mathrm{~F}$ \\
\hline$C_{I_{-}} C_{g d}$ & $8.53126 \times 10^{-12} \mathrm{~F}$ \\
\hline$C_{2} C_{g d}$ & $1.78482 \times 10^{-12} \mathrm{~F}$ \\
\hline$A_{-} C_{g d}$ & 2.76139 \\
\hline$B_{-} C_{g d}$ & $3.050874 \times 10^{1}$ \\
\hline$V_{m_{-}} C_{g d}$ & $2.71477 \mathrm{~V}$ \\
\hline$V_{p_{-}} C_{g d}$ & $4.5233 \times 10^{-1} \mathrm{~V}$ \\
\hline
\end{tabular}

표 4. GaN HEMT 단위 소자에 대하여 추출된 비선형 모 델 파라미터 값들 $\left(C_{g d}\right.$ model $)$

Table 4. Nonlinear model parameters extracted for a GaN HEMT unit device $\left(C_{g d}\right.$ model $)$.

\begin{tabular}{|c|c|}
\hline Parameter & Value \\
\hline$C_{0} C_{g d}$ & $1.79422 \times 10^{-13} \mathrm{~F}$ \\
\hline$C_{I_{-}} C_{g d}$ & $1.03653 \times 10^{-12} \mathrm{~F}$ \\
\hline$C_{2} C_{g d}$ & $2.51129 \times 10^{-12} \mathrm{~F}$ \\
\hline$A_{-} C_{g d}$ & $3.72377 \times 10^{-2}$ \\
\hline$B_{-} C_{g d}$ & 2.44076 \\
\hline$V_{m_{-}} C_{g d}$ & $5.48254 \mathrm{~V}$ \\
\hline$V_{p_{-}} C_{g d}$ & $-3.6 \mathrm{~V}$ \\
\hline
\end{tabular}

표 5. GaN HEMT 단위 소자에 대하여 추출된 비선형 모 델 파라미터 값들 $\left(C_{d s}\right.$ model $)$

Table 5. Nonlinear model parameters extracted for a $\mathrm{GaN}$ HEMT unit device $\left(C_{d s}\right.$ model).

\begin{tabular}{|c|c|}
\hline Parameter & Value \\
\hline$C_{0} C_{g d}$ & $3.22078 \times 10^{-15} \mathrm{~F}$ \\
\hline$C_{I_{-}} C_{g d}$ & $3.59715 \times 10^{-12} \mathrm{~F}$ \\
\hline$C_{2} C_{g d}$ & $2.91272 \times 10^{-12} \mathrm{~F}$ \\
\hline$A_{-} C_{g d}$ & 2.40076 \\
\hline$B_{-} C_{g d}$ & $6.0994 \times 10^{-2}$ \\
\hline$V_{m_{-}} C_{g d}$ & $1.34 \mathrm{~V}$ \\
\hline$V_{P_{-}} C_{g d}$ & $1 \times 10^{1} \mathrm{~V}$ \\
\hline
\end{tabular}

단위 소자의 열저항 모델을 구하기 위하여 $25{ }^{\circ} \mathrm{C}, 50{ }^{\circ} \mathrm{C}$, $85{ }^{\circ} \mathrm{C}$ 에서 PIV 특성을 측정하고, Del Alamo 방법 $[17],[18],[24]$ 을 이용하여 $R_{t h}$ 를 구하였으며, 그 값은 $3.75{ }^{\circ} \mathrm{C} / \mathrm{W}$ 이다. 트 래핑 효과 모델은 게이트 전압과 드레인 전압의 변화에 따른 드레인 전류의 감소를 측정함으로써 얻어진다 ${ }^{[17]}$ [19].

그림 3에 단위 소자 모델을 검증하기 위한 PIV 특성을 나타내었다. $V_{d q}=40 \mathrm{~V}, I_{d q}=350 \mathrm{~mA}$ 의 동작 조건에서 측정 및 시뮬레이션 결과를 비교하였다. 소자들이 제작된 공정 의 Process Control Monitoring 소자의 $I d_{\max }$ 가 $0.95 \mathrm{~A} / \mathrm{mm}$ 이 므로 PIV 측정을 위한 프로브와 bias Tee의 정격 전류가 충분히 커야 한다. 측정에 사용된 프로브는 $\mathrm{MPI}$ 사의 T26P이며, bias Tee는 Keysight사의 11612A option 001로 정격 전류가 $\mathrm{DC} 2 \mathrm{~A}$ 이며, 동작 주파수는 $0.4 \sim 26.5 \mathrm{GHz}$ 이다. PIV 측정시 정격 전류를 초과하지 않도록 바이어스 전압 펄스폭 $1 \mu \mathrm{s}, \mathrm{RF}$ 펄스폭 $0.6 \mu \mathrm{s}, \mathrm{VNA}$ 측정 펄스폭 이 $0.3 \mu \mathrm{s}$ 가 되도록 제어하였다.

단위 소자의 GaN HEMT 대신호 모델을 검증하기 위하 여 $S$-파라미터 특성을 측정하고, $\mathrm{ADS}$ 를 활용하여 시뮬레 이션 결과와 비교하였다. $V_{d s}=40 \mathrm{~V}, I_{d q}=350 \mathrm{~mA}$ 의 바 이어스 조건에서 동작주파수 $0.5 \sim 12 \mathrm{GHz}$ 의 $S$-파라미터 측정과 시뮬레이션을 수행하였으며, 그 결과를 그림 4에 나타내었다.

단위 소자의 GaN HEMT 대신호 모델 검증을 위한 로

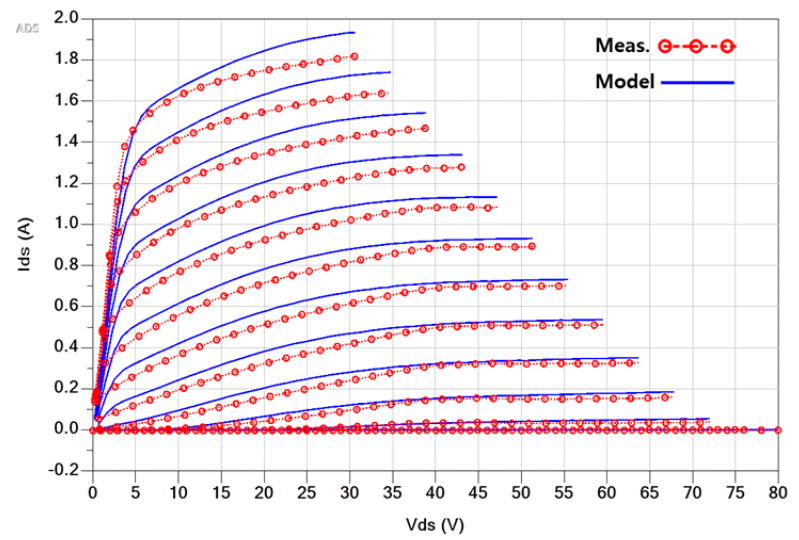

그림 3. GaN HEMT 단위 소자의 pulsed-IV 특성 결과

Fig. 3. Measured and simulated pulsed-IV characteristics of the GaN HEMT unit device. 


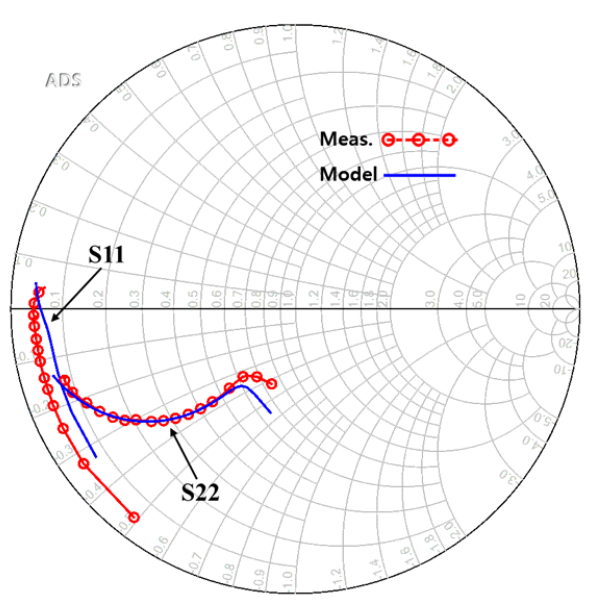

(a) $S_{11}$ 과 $S_{22}$

(a) $S_{11}$ and $S_{22}$

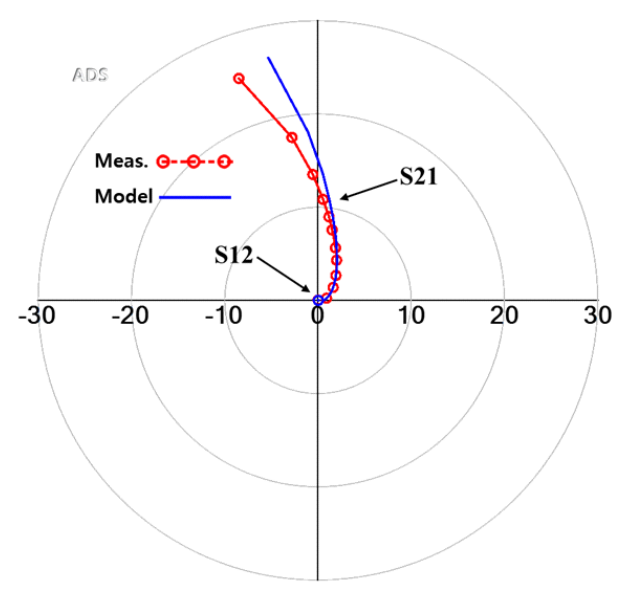

(b) $S_{12}$ 와 $S_{21}$

(b) $S_{12}$ and $S_{21}$

그림 4. 단위 소자의 $S$-파라미터 측정 및 모델 결과

Fig. 4. Measured and simulated $S$-parameter results of the unit device.

드-풀 측정은 $3.2 \mathrm{GHz}$ 주파수에서 수행하였다. 그림 5에 최대 출력과 효율을 얻는 부하 임피던스와 궤적에 대한 측정 및 시뮬레이션 결과를 나타내었으며, 최대 출력 부 하 임피던스 점과 최대 효율 부하 임피던스 점에서의 특 성들을 표 6과 표 7에 나타내었다. 모델을 이용한 시뮬레 이션 결과와 측정 결과가 서로 잘 일치함을 볼 수 있다.

최대 출력 부하 임피던스 점에서 입력 신호의 크기를 가변하면서 출력 전력, 이득, 효율 특성에 대한 시뮬레이

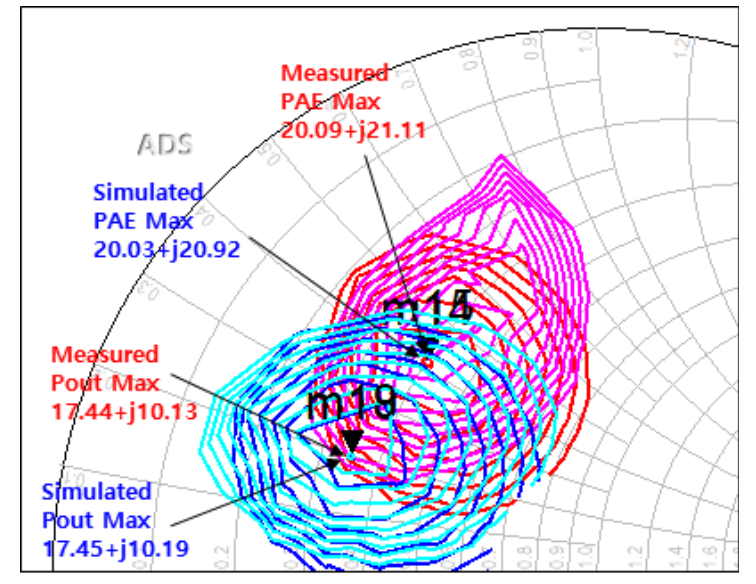

그림 5. 단위 소자의 로드-풀 측정 및 시뮬레이션 결과

Fig. 5. Measured and simulated load-pull results of the unit device.

표 6. 단위 소자에 대한 최대 출력 부하 임피던스 점 특성 Table 6. Characteristics at the maximum output power load impedance of the unit device.

\begin{tabular}{|c|c|c|}
\hline & Model & Measured \\
\hline Load impedance $[\Omega]$ & $17.45+\mathrm{j} 10.19$ & $17.44+\mathrm{j} 10.13$ \\
\hline Output power [dBm] & 43.87 & 44.08 \\
\hline Power gain [dB] & 16.87 & 17.09 \\
\hline PAE [\%] & 57.32 & 54.93 \\
\hline
\end{tabular}

표 7. 단위 소자에 대한 최대 효율 부하 임피던스 점 특성 Table 7. Characteristics at the maximum efficiency load impedance of the unit device.

\begin{tabular}{|c|c|c|}
\hline & Model & Measured \\
\hline Load impedance $[\Omega]$ & $20.03+\mathrm{j} 20.92$ & $20.09+\mathrm{j} 21.11$ \\
\hline Output power $[\mathrm{dBm}]$ & 43.41 & 43.42 \\
\hline Power gain $[\mathrm{dB}]$ & 16.11 & 16.08 \\
\hline PAE [\%] & 58.39 & 60.67 \\
\hline
\end{tabular}

션 및 측정 결과를 그림 6에 나타내었다.

10 -핑거 소자의 GaN HEMT 대신호 모델을 이용한 시 뮬레이션을 통하여 $43.87 \mathrm{dBm}$ 의 최대 출력, $16.87 \mathrm{~dB}$ 의 전력 이득, $57.32 \%$ 의 전력 부가 효율을 얻었다. 10-핑거 소자의 로드-풀 측정을 통하여 $44.08 \mathrm{dBm}$ 의 최대 출력, $17.09 \mathrm{~dB}$ 의 전력 이득, $54.93 \%$ 의 전력 부가 효율을 확인 하였으며, 시뮬레이션과 측정 결과는 서로 잘 일치하였다. 


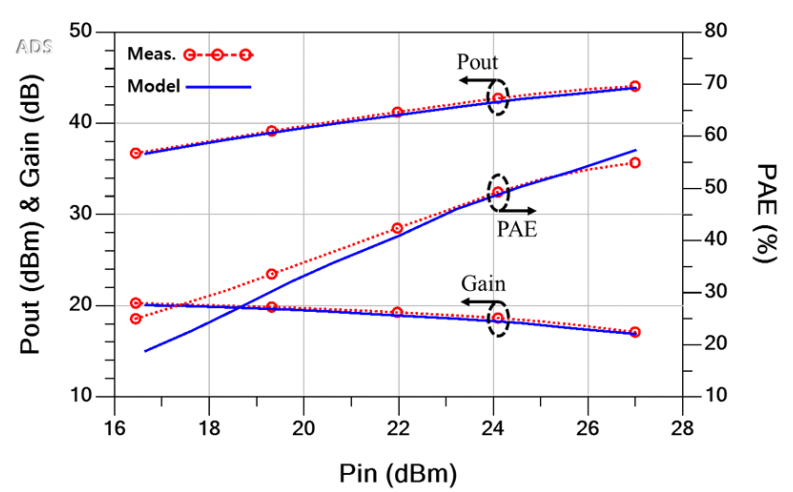

그림 6 최대 출력 부하 임피던스 조건에서 단위소자의 입력전력에 따른 출력 전력성능 특성

Fig. 6. Output power performance of the unit device with the input power under the maximum power load impedance condition.

\section{III. 병렬 확장형 대면적 소자 모델}

높은 출력을 내는 대면적 소자의 경우, 소모 전류가 커 서 온-웨이퍼 프로브 장비로 직접 측정하기 어렵다. 대면 적 소자를 패키징한 다음 측정된 데이터를 기반으로 모 델링을 수행할 경우, 패키징에 따른 추가적인 회로 성분 의 영향과 기생 성분의 영향으로 정확한 대면적 소자 자 체만의 비선형 모델을 구현하기 어렵다. 따라서 소자 자 체만의 비선형 모델을 얻기 위해서는 디임베딩 과정이 필요하며, 이러한 디임베딩 과정 또한 측정 에러를 포함 하고 있을 뿐만 아니라, 제작과 측정에 따른 비용과 많은 시간이 요구된다. 따라서 측정 가능한 작은 소자의 특성 을 온-웨이퍼 프로브 장비로 측정하여 GaN HEMT 대신 호 모델을 제작한 다음 대면적 소자 모델로 확장하는 방 법이 많이 사용되고 있다 ${ }^{[4]-[8]}$.

80-핑거 $\mathrm{GaN} \mathrm{HEMT}$ 소자는 그림 7(a)에 보이는 것과 같이 앞 절에서 설명한 10 -핑거 GaN HEMT 단위 소자 8 개가 병렬로 연결된 형태이다. 인접한 단위 소자는 게이 트 전극과 드레인 전극끼리 단락으로 연결되어 있으며, 단위 소자 사이에는 소스 전극이 있어 후면 비아를 통하 여 접지로 연결되는 구조이다. 80-핑거 GaN HEMT 소자 에 대한 병렬 확장형 대면적 소자 모델을 그림 7(b)에 같 이 나타내었다. 앞 절에서 제작한 단위 소자 모델을 적용 하였고 인접한 단위 소자의 게이트와 드레인 전극을 단

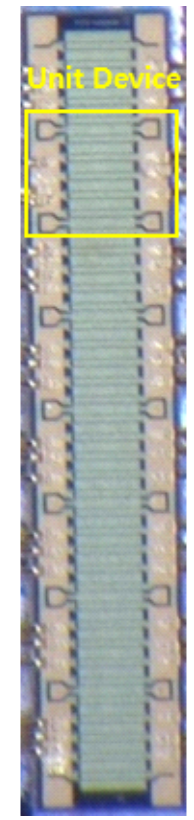

(a) 소자 사진

(a) Device photograph

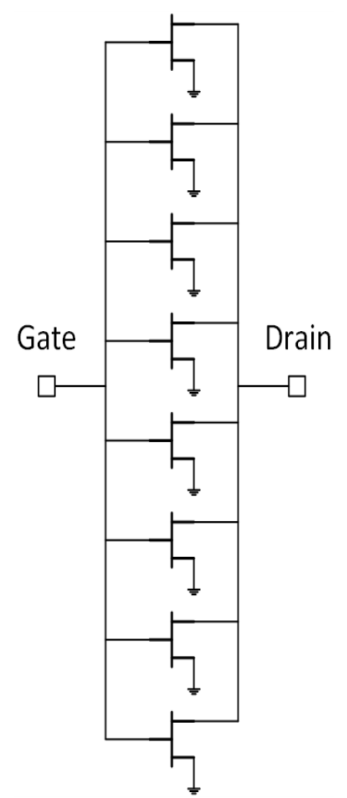

(b) 등가회로 모델

(b) Equivalent circuit model
그림 7. 단위 소자 8 개로 구성된 대면적 GaN HEMT 소자 사진과 병렬 확장형 대신호 모델

Fig. 7. Photograph of the large-sized GaN HEMT with 8 unit devices and its equivalent circuit model.

락으로 연결하였으며, 소스를 접지로 연결하였다. 단위 소자 사이의 열적 결합 효과는 고려하지 않고 동일한 $R_{t h}$ 값을 적용하였다.

제작된 80-핑거 GaN HEMT 소자의 모델을 검증하기 위하여 로드-풀 측정을 수행하였다. 로드-풀 측정을 위하 여 제작한 대면적 소자의 패키지 사진을 그림 8에 나타내 었다. 단위 소자의 게이트와 드레인 패드에 각각 3개씩 와이어 본딩이 되어 있다. GaN HEMT 칩을 패키지하기 위하여 $\mathrm{CPCl} 41$ 기판 위에 유테틱 본딩으로 접합하였으 며, 패키지 리드(lead)는 Alloy42를 사용하고, 절연용 세라 믹은 $\mathrm{Al} 2 \mathrm{O} 3$ 를 사용하였다. 로드풀 측정을 위한 기준면을 그림 8에 나타내었으며, 본딩와이어 프로파일과 게이트 및 드레인 리드의 길이를 실측을 통하여 구한 다음 $3 \mathrm{D}$ $\mathrm{EM}$ 시뮬레이션을 수행하여 전기적 길이를 추출하고, 입 력단에 $15.91^{\circ}$, 출력단에 $13.64^{\circ}$ 의 위상 이동을 시뮬레이 션 상에서 반영하였다.

80-핑거 대면적 소자를 패키징한 다음 로드-풀 측정을 


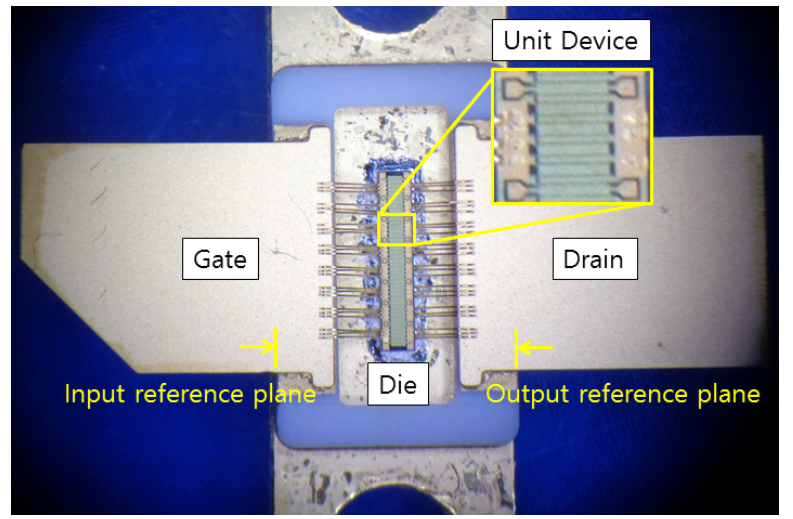

그림 8. 10-핑거 트랜지스터 단위 소자 8개로 구성된 대 면적 소자의 패키지 사진

Fig. 8. Photograph of the packaged large-sized device with eight 10-finger transistor unit devices.

수행하여 제작된 대신호 모델을 비교하였다. 80-핑거 대 면적 소자 로드-풀 측정은 펄스 폭 $30 \mu \mathrm{s}$, duty cycle $3.4 \%$ 의 펄스 신호를 인가하여 측정하였다. 그림 9에 최대 출 력과 효율을 얻는 부하 임피던스와 궤적에 대한 측정 및 시뮬레이션 결과를 나타내었으며, 최대 출력 부하 임피던 스 점과 최대 효율 부하 임피던스 점에서의 특성들을 표 8과 표 9에 나타내었다. 모델을 이용한 시뮬레이션 결과

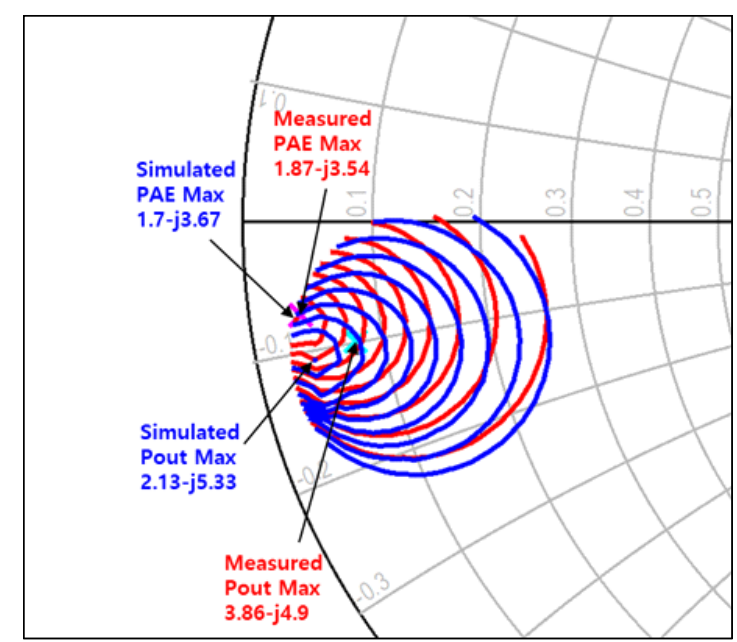

그림 9. 대면적 소자의 로드-풀 특성 측정 및 시뮬레이 션 결과

Fig. 9. Measured and simulated load-pull results of the large-sized device.
표 8. 대면적 소자에 대한 최대 출력 부하 임피던스 점의 특성

Table 8. Characteristics at the maximum output power load impedance of the large-sized device.

\begin{tabular}{|c|c|c|}
\hline & Model & Measured \\
\hline Load impedance $[\Omega]$ & $2.13-\mathrm{j} 5.33$ & $3.86-\mathrm{j} 4.90$ \\
\hline Output power $[\mathrm{dBm}]$ & 52.23 & 51.44 \\
\hline Power gain $[\mathrm{dB}]$ & 13.43 & 12.71 \\
\hline PAE $[\%]$ & 49.16 & 46.84 \\
\hline
\end{tabular}

표 9. 대면적 소자에 대한 최대 효율 부하 임피던스 점의 특성

Table 9. Characteristics at the maximum efficiency load impedance of the large-sized device.

\begin{tabular}{|c|c|c|}
\hline & Model & Measured \\
\hline Load impedance $[\Omega]$ & $1.70-\mathrm{j} 3.67$ & $1.87-\mathrm{j} 3.54$ \\
\hline Output power $[\mathrm{dBm}]$ & 50.44 & 50.31 \\
\hline Power gain $[\mathrm{dB}]$ & 12.08 & 11.88 \\
\hline PAE $[\%]$ & 54.48 & 49.66 \\
\hline
\end{tabular}

와 측정 결과가 서로 잘 일치함을 볼 수 있다.

단위 소자의 경우와 비교할 때 효율에 대한 모델과 측 정 결과의 차이가 큰 것을 볼 수 있다. 단위 소자의 로드풀 측정은 온-웨이퍼 프로브 시스템을 이용함으로써 칩 의 게이트와 드레인 패드에 프로브를 연결할 수 있었지 만, 대면적 소자의 로드-풀 측정은 칩을 패키지한 다음 테 스트 픽스쳐를 통하여 전류가 공급되는 구조이며, 짧은 펄스 폭을 가지는 전류를 전류 프로브로 측정하므로 단 위 소자의 로드-풀 측정에 비하여 전류의 측정 정확도가 낮기 때문이라고 생각된다.

최대 출력 부하 임피던스 점에서 입력 신호의 크기를 가변하면서 출력 전력, 이득, 효율 특성에 대한 시뮬레이 션 및 측정 결과를 그림 10 에 나타내었다.

80-핑거 소자의 GaN HEMT 대신호 모델을 이용한 시 뮬레이션을 통하여 $52.23 \mathrm{dBm}$ 의 최대 출력, $13.43 \mathrm{~dB}$ 의 전력 이득, $49.16 \%$ 의 전력 부가 효율을 얻었다. 80 -핑거 소자의 로드-풀 측정을 통하여 $51.44 \mathrm{dBm}$ 의 최대 출력, $12.71 \mathrm{~dB}$ 의 전력 이득, $46.84 \%$ 의 전력 부가 효율을 확인 하였으며, 시뮬레이션과 측정 결과는 서로 잘 일치하였다. 


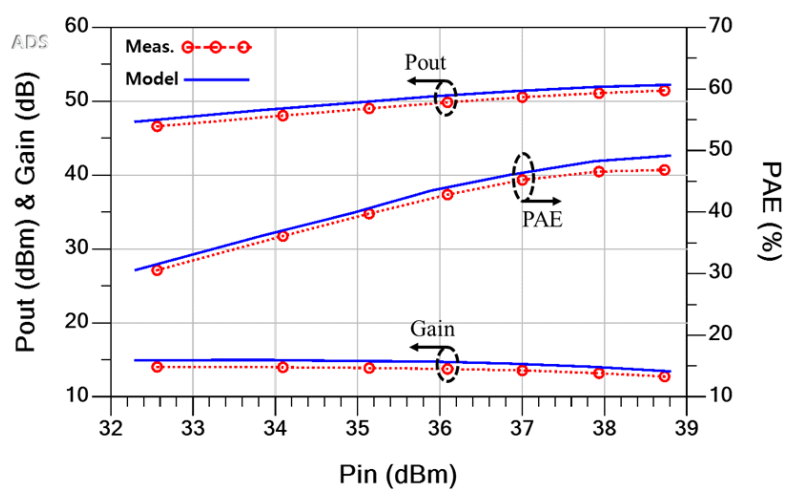

그림 10. 최대 출력 부하 임피던스 조건에서 대면적 소 자의 입력전력에 따른 출력 전력성능 특성

Fig. 10. Output power performance of the large-sized device with the input power under the maximum power load impedance condition.

\section{$\mathrm{V}$. 결 론}

본 논문에서는 $140 \mathrm{~W}$ 급 전력 증폭 소자에 대한 병렬 확장형 GaN HEMT 대신호 모델을 제시하였다. 제작된 모델은 8 개의 단위 소자 모델이 병렬 확장형으로 연결된 구조이며, 단위 소자의 대신호 모델은 AMCAD FET 모델 을 기반으로 제작되었다. $\mathrm{AMCAD}$ 사의 $\mathrm{IVCAD}^{\mathrm{TM}}$ 프로그 램과 Keysight사의 PNA-X ${ }^{\mathrm{TM}}$ 네트워크 분석기를 이용하여 단위 소자의 GaN HEMT 대신호 모델 파라미터를 추출하 였다. 단위 소자의 대신호 모델은 10-핑거 소자를 온-웨이 퍼 로드-풀 측정을 수행하여 검증하였으며, 대면적 소자 의 대신호 모델은 80-핑거 소자를 패키징한 다음 로드-풀 측정을 수행하여 검증하였다. 제작된 대신호 모델은 능동 위상 배열 레이다 등에 핵심 소자로 사용되는 고출력 전 력 증폭기의 설계에 유용하게 활용될 수 있을 것이다.

\section{References}

[1] D. W. Runton, B. Trabert, J. B. Shealy, and R. Vetury, "History of GaN: High-power RF gallium nitride(GaN) from infancy to manufacturable process and beyond," IEEE Microwave Magazine, vol. 14, no. 3, pp. 82-93, May 2013.

[2] H. S. Kang, K. T. Bae, I. J. Lee, H. W. Cha, B. G. Min,
D. M. Kang, and D. W. Kim, "X-band $50 \mathrm{~W}$ pulse-mode GaN HEMT internally matched power amplifier," The Journal of Korean Institute of Electromagnetic Engineering and Science, vol. 27, no. 10, pp. 892-899, Oct. 2016. [3] H. S. Kwon, G. W. Choi, S. M. Lee, and D. W. Kim, "S-band 300-W GaN HEMT internally matched power amplifier," The Journal of Korean Institute of Electromagnetic Engineering and Science, vol. 31, no. 1, pp. 43-50, Jan. 2020.

[4] J. P. Mondal, "Distributed scaling approach of MESFETs and its comparison with the lumped-element approach," IEEE Transactions on Microwave Theory and Techniques, vol. 37, no. 7, pp. 1085-1090, Jul. 1989.

[5] D. Resca, A. Santarelli, A. Raffo, R. Cignani, G. Vannini, and F. Filicori, et al., "Scalable nonlinear FET model based on a distributed parasitic network description," IEEE Transactions on Microwave Theory and Techniques, vol. 56, no. 4, pp. 755-766, Apr. 2008.

[6] A. Xiong, C. Charbonniaud, E. Gatard, and S. Dellier, "A scalable and distributed electro-thermal model of $\mathrm{AlGaN} / \mathrm{GaN}$ HEMT dedicated to multi-fingers transistors," in 2010 IEEE Compound Semiconductor Integrated Circuit Symposium(CSICS), Monterey, CA, Oct. 2010, pp. 1-4.

[7] S. Halder, J. McMacken, and J. Gering, "First pass multi cell modeling strategy for GaN package device," in 2014 IEEE Compound Semiconductor Integrated Circuit Symposium(CSICS), La Jolla, CA, Oct. 2014, pp. 1-4.

[8] F. Heinz, D. Schwantuschke, A. Leuther, and O. Ambacher, "Highly scalable distributed high electron mobility transistor model," in 2019 IEEE Asia-Pacific Microwave Conference(APMC), Singapore, Dec. 2019, pp. 1286-1288.

[9] D. Resca, A. Raffo, A. Santarelli, G. Vannini, and F. Filicori, "Extraction of an extrinsic parasitic network for accurate mm-Wave FET scalable modeling on the basis of full-wave EM simulation," in 2008 IEEE MTT-S International Microwave Symposium Digest, Atlanta, GA, 
Jun. 2008, pp. 1405-1408.

[10] D. Resca, A. Raffo, A. Santarelli, G. Vannini, and F. Filicori, "Scalable equivalent circuit FET model for MMIC design identified through FW-EM analyses," IEEE Transactions on Microwave Theory and Techniques, vol. 57, no. 2, pp. 245-253, Feb. 2009.

[11] J. A. Zamudio-Flores, G. Kompa, "Improved measurementbased extraction algorithm of a comprehensive extrinsic element network for large-size GaN HEMTs," in the Proceedings of the 5th European Microwave Integrated Circuits Conference, Paris, Sep. 2010, pp. 250-253.

[12] Y. Xu, W. Fu, C. Wang, C. Ren, H. Lu, and W. Zheng, et al., "A scalable GaN HEMT large-signal model for high-efficiency RF power amplifier design," Journal of Electromagnetic Waves and Applications, vol. 28, no. 15, pp. 1888-1895, Sep. 2014.

[13] Y. Xu, C. Wang, H. Sun, Z. Wen, Y. Wu, and R. Xu, et al., "A scalable large-signal multiharmonic model of $\mathrm{AlGaN} / \mathrm{GaN}$ HEMTs and its application in C-band high power amplifier MMIC," IEEE Transactions on Microwave Theory and Techniques, vol. 65, no. 8, pp. 2836-2846, Aug. 2017.

[14] Q. Wu, Y. Xu, Y. Chen, Y. Wang, W. Fu, B. Yan, and R. $\mathrm{Xu}$, "A scalable multiharmonic surface-potential model of AlGaN/GaN HEMTs," IEEE Transactions on Microwave Theory and Techniques, vol. 66, no. 3, pp. 1192-1200, Mar. 2018.

[15] G. Torregrosa, J. Grajal, M. Peroni, A. Serino, A. Nanni, and A. Getronio, "Large-signal modeling of power GaN HEMTs including thermal effects," in the Proceedings of the 2007 European Microwave Integrated Circuits Conference, Munich, Oct. 2007, pp. 36-39.

[16] J. B. King, T. J. Brazil, "Nonlinear electrothermal GaN HEMT model applied to high-efficiency power amplifier design," IEEE Transactions on Microwave Theory and
Techniques, vol. 61, no. 1, pp. 444-454, Jan. 2013.

[17] AMCAD, "IVCAD 3.8." Available: https://www.amcadengineering.com/software/ivcad-3-8

[18] AMCAD, "MT930M1/M2A - HEMT compact model extractor, operation manual v3.6." Available: https://www. amcad-engineering.com/pp. 26-32.

[19] T. Gasseling, "Compact transistor models: The raodmap to first-pass amplifier design success," Microwave Journal, vol. 55, no. 3, pp. 74-86, 2012.

[20] C. Charbonniaud, A. Xiong, S. Dellier, O. Jardel, and R. Quéré, "A non linear power HEMT model operating in multi-bias conditions," in the Proceedings of the $5^{\text {th }}$ European Microwave Integrated Circuits Conference (EuMA), Paris, Sep. 2010, pp. 134-137.

[21] G. Dambrine, A. Cappy, F. Heliodore, and E. Playez, "A new method for determining the FET small-signal equivalent circuit," IEEE Transactions on Microwave Theory and Techniques, vol. 36, no. 7, pp. 1151-1159, Jul. 1988.

[22] M. Berroth, R. Bosch, "High-frequency equivalent circuit of GaAs FETs for large-signal applications," IEEE Transactions on Microwave Theory and Techniques, vol. 39, no. 2, pp. 224-229, Feb. 1991.

[23] C. Charbonniaud, T. Gasseling, "VNA based load pull harmonic measurement de-embedding dedicated to waveform engineering," in 2015 IEEE International Conference on Microwaves, Communications, Antennas and Electronic Systems(COMCAS), Tel Aviv, Nov. 2015, pp. 1-6.

[24] J. Hoh, J. A. del Alamo, U. Chowdhury, T. M. Chou, H. Q. Tserng, and J. L. Jimenez, "Measurement of channel temperature in GaN high-electron mobility transistors," IEEE Transactions on Electron Devices, vol. 56, no. 12, pp. 2895-2901, Dec. 2009. 
권 호 상 [국방과학연구소/책임연구원]

https://orcid.org/0000-0001-5133-296X

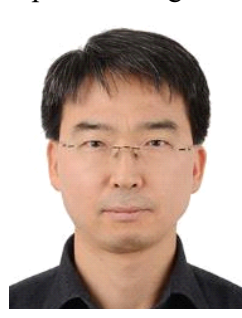

1995년 2월: 경북대학교 전자공학과 (공학

사)

1997년 2월: 경북대학교 전자공학과 (공학 석사)

2018년 3월 현재: 충남대학교 전파정보

통신공학과 박사 과정

1997년 3월 1999년 2월: 대우전자 연구 원

1999년 3월 현재: 국방과학연구소 책임연구원

[주 관심분야] 레이다, 레이다용 송수신기, $\mathrm{RF}$ 송수신 모듈, $\mathrm{RF}$ power Amplifier, 비선형 모델링 등

정 종 헌 [한화시스템/전문연구원]

https://orcid.org/0000-0003-2407-5851

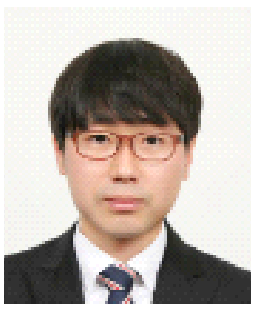

2008년 2월: 충남대학교 전기정보통신공 학부 (공학사)

2010년 2월: 광주과학기술원 정보통신공 학부 (공학석사)

2016년 2월: 광주과학기술원 정보통신공 학부 (공학박사)

2016년 9월 현재: 한화시스템 전문연구

원

[주 관심분야] GaN HEMT, RF Power Amplifier, IMFET, 비선형 모델링, $\mathrm{EMC}$ 등
김 동 욱 [충남대학교/교수]

https://orcid.org/0000-0003-1913-4714

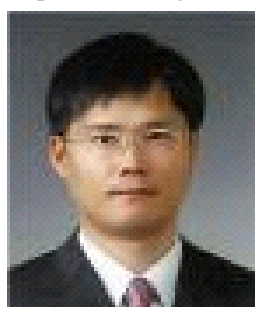

1990년 2월: 한양대학교 전자통신공학과 (공학사)

1992년 2월: 한국과학기술원 전기및전자 공학과 (공학석사)

1996년 8월: 한국과학기술원 전기및전자 공학과 (공학박사)

1991년 8월 2000년 5월: LG 종합기술원

선임연구원

2000년 6월 2002년 8월: (주텔레포스 연구소장

2002년 9월 2004년 9월: 에스원기술연구소 응용기술팀장

2009년 6월 2009년 12월: ETRI 초빙연구원

2010년 1월 2011년 1월: 미국 UCSD 방문교수

2004년 10월 현재: 충남대학교 전파정보통신공학과 교수

[주 관심분야] 초고속 및 초고주파 집적회로, 마이크로파 및 밀 리미터파 전력증폭기 모듈, 근거리 레이다 모듈 